\title{
Fused teeth in the primary dentition: clinical case report
}

\section{Fusão dentária em dentição decídua: estudo de caso clínico}

\author{
Amanda Carolina COSTA ${ }^{1}$ iD https://orcid.org/0000-0003-0302-1141 \\ Bárbara Salles do NASCIMENTO' ${ }^{1}$ iD https://orcid.org/0000-0001-8446-3341 \\ Jéssica Luciana Cruz SILVA ${ }^{1}$ iD https://orcid.org/0000-0001-6288-708X \\ Alice Machado Carvalho SANTOS² iD https://orcid.org/0000-0002-6864-246X \\ Suzana Coulaud da Costa CRUZ ${ }^{3}$ iD https://orcid.org/0000-0001-5830-251X \\ Maria Luiza da Matta Felisberto FERNANDES ${ }^{3}$ iD https://orcid.org/0000-0002-5120-1449
}

\section{ABSTRACT}

Fused teeth are a developmental anomaly involving the union of two dental germs at the crown, root or pulp. This type of anomaly occurs during intraosseous development, resulting in a morphologically irregular tooth that can affect both the primary and permanent dentition. Clinical problems involving esthetics, a lack of space and greater susceptibility to caries are often associated with fused teeth. This type of anomaly is easily confused with dental twinning, which has similar clinical features but emerges from a single dental germ. The aim of the present study was to report a clinical case of the fusion of two deciduous mandibular incisors, describe prospects for treating this anomaly and discuss its repercussions during the development of the dentition. Extraction of the fused tooth was performed and orthodontic treatment was recommended for esthetic and functional improvements. Integrated planning involving both Pediatric Dentistry and Orthodontics provided a better treatment option.

Indexing terms: Fused teeth. Orthodontics. Tooth, deciduous.

\section{RESUMO}

A fusão dentária é classificada como uma alteração de desenvolvimento referente à união de dois germes dentários, podendo incluir coroa, raiz e polpa. Este tipo de alteração ocorre durante o desenvolvimento intraósseo, resultando em um dente morfologicamente irregular, podendo acometer tanto a dentição decídua quanto a permanente. Frequentemente são associados problemas clínicos como alterações estéticas, falta de espaço e maior susceptibilidade a lesões cariosas. É importante ressaltar que a fusão é comumente confundida com a geminação dentária, que apresenta o mesmo aspecto clínico em boca, porém é resultante de um único germe dentário. O objetivo deste estudo é apresentar um caso clínico de fusão de dois incisivos inferiores decíduos, as perspectivas de tratamento da anomalia e discutir sua repercussão durante o desenvolvimento da dentição. Realizou-se a exodontia do elemento citado e o planejamento do tratamento ortodôntico recomendado foi discutido visando a melhora dos aspectos funcional e estético. Um planejamento integrado entre a Odontopediatria e Ortodontia proporcionou uma melhor alternativa de tratamento.

Termos de indexação: Dentes fusionados. Ortodontia. Dente decíduo.

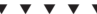

${ }^{1}$ Centro Universitário Newton Paiva, Faculdade de Odontologia, Departamento de Odontopediatria. Av. Silva Lobo, 1730, Nova Granada, 30431-262, Belo Horizonte, MG, Brasil. E-mail: amandacarol_lorah@hotmail.com>.

2 Universidade Federal de Minas Gerais, Faculdade de Odontologia, Departamento de Saúde Bucal da Criança e do Adolescente. Belo Horizonte, MG, Brasil.

${ }^{3}$ Centro Universitário Newton Paiva, Faculdade de Odontologia, Departamento de Ortodontia. Belo Horizonte, MG, Brasil. Correspondence to: MLMF Fernandes. E-mail: <marialuizadamatta@gmail.com>.

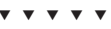

How to cite this article

Costa AC, Nascimento BS, Silva JLC, Santos AMC, Cruz SCC, Fernandes MLMF. Fused teeth in the primary dentition: clinical case report. RGO, Rev Gaúch Odontol. 2020;68:e20200051. http://dx.doi.org/10.1590/1981-863720200005120190100 


\section{INTRODUCTION}

Fused teeth are characterized by the union of two teeth during intraosseous development. The teeth may be united by the crown, pulp chamber or root, depending on the time at which the fusion of the germs occurred during their development. The prevalence of fused teeth in the primary dentition ranges from $0.1 \%$ to $2.5 \%$, depending on the population studied, the diagnostic method (with or without $x$-ray) and ethnicity of the individual $[1,2]$. Fused primary teeth occur four times more often in the anterior region of the mandible compared to the maxilla [3].

It is common to find fused teeth in the region of the incisors and canines. The occurrence may be unilateral or bilateral, involving either the upper or lower arch [4]. The primary incisors are the most frequently affected [5]. This type of anomaly may also affect the permanent dentition, but the occurrence of fused permanent posterior teeth is rare.

Fusion may occur with a neighboring tooth or a supernumerary tooth, which makes the diagnosis more difficult [4]. The treatment plan for this type of anomaly should consider the oral cavity and occlusion as a whole, rather than merely the local developmental abnormality [6]. The repercussions of fused teeth are malocclusion, a lack of space and delayed eruption of the permanent successor [7]. Delayed eruption is due to the greater root area of the fused tooth in relation to the size of the crown of the permanent successor, which may lead to its impaction [4].

Malocclusion is widely discussed in the literature as a factor that exerts a negative impact on the quality of life of children and adolescents [8]. According to Kumar et al. [6], the clinical problems found with fused teeth are spacing between the teeth, misaligned teeth, asymmetry in the arch and intercuspation, esthetic problems and the possibility of permanent tooth agenesis associated with fused teeth in the primary dentition [4]. The treatment options described in the literature are extraction in cases of impaction of the permanent successor, endodontic treatment when the pulp is compromised, orthodontic treatment when there is a lack of space, dental separation when the fusion only occurs in the crown portion and esthetic treatment if there are complaints on the part of the patient [5].

The aim of the present study was to report a clinical case of the fusion of two primary mandibular incisors, describe the treatment prospects of the anomaly and discuss its repercussions during the development of the dentition. Treatment was planned considering function, esthetics and psychological factors.

\section{CASE REPORT}

A six-year-old female patient (PCC) initiated dental treatment at the Newton Paiva University Center in the city of Belo Horizonte, Brazil. The guardian's main complaint was the occurrence of an unusual tooth shape. There was no report of family members with this type of anomaly or any external triggering factor.

The analysis of the panoramic and periapical radiographs led to the diagnosis of a fused, possibly retained primary tooth, referring to teeth 81 and 82 (figures 1a and $1 \mathrm{~b})$. The fused tooth exhibited incipient root resorption related to the rhizogenesis of the permanent successor (tooth 41); physiological resorption was not sufficient for the occurrence of exfoliation and the subsequent eruption of tooth 41 (Figures $1 \mathrm{a}$ and $1 \mathrm{~b}$ ). Clinically, the primary teeth were sound. Moreover, tooth 31 was already in

(a)

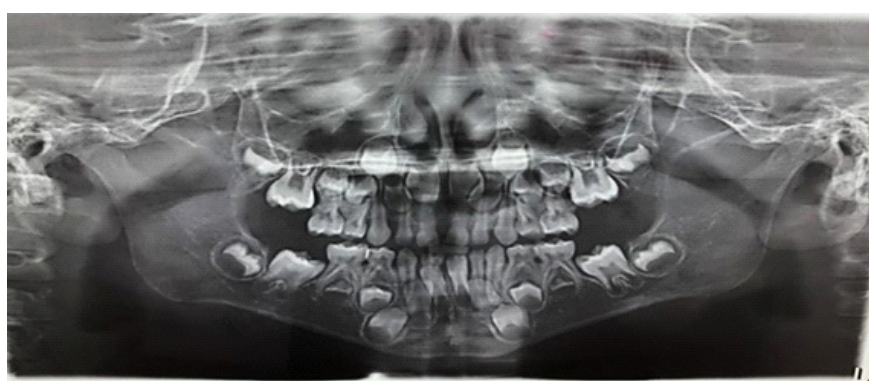

(b)

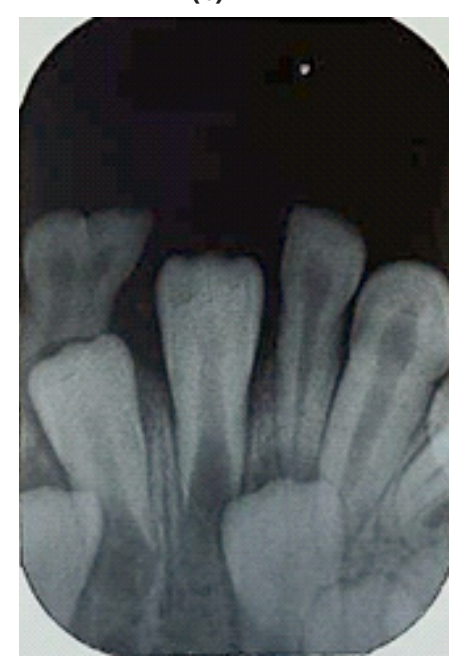

Figure 1. Radiographs of patients on October 7th, 2017: a) panoramic x-ray; b) periapical x-ray of mandibular incisors. 
the eruption phase, whereas tooth 41 was not present in the arch (figures $1 \mathrm{a}$ and $1 \mathrm{~b}$ ). Extraction was the indicated treatment option to enable the eruption of the impacted permanent successor. The incipient root resorption was observed after the extraction of the fused tooth (figure 2).

With the normal eruption sequence, the permanent maxillary central incisors (teeth 11 and 21) should be closer to the occlusal line than the permanent maxillary lateral incisors (teeth 12 and 22). However, a lack of space was found for the lateral incisors and canines. Thus, we concluded that an inversion in the normal eruption order had occurred between the permanent maxillary central and lateral incisors (figure 1a).

(a)

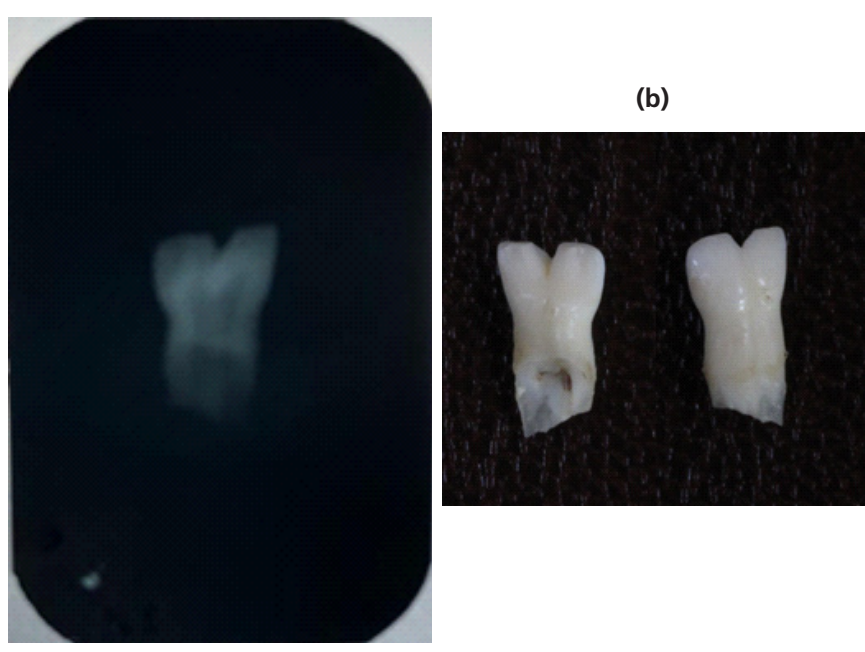

Figure 2. Incipient root resorption of fused teeth 81 and 82 found after extraction. a) x-ray; b) photograph.

The follow-up of the case was scheduled for two months after the extraction of the fused tooth, when the patient had completed seven years of age. A complete orthodontic documentation was performed with a new panoramic radiograph for the orthodontic assessment (figure 3).

The analysis of the most recent radiograph revealed that the inversion between the permanent maxillary central (teeth 11 and 21) and lateral (teeth 12 and 22) incisors had diminished. The teeth were more level in relation to the occlusal line. However, the tooth eruption order was still inverted, with a favorable prognosis of self-correction during the development of the permanent dentition. A lack of space was found for the corrected positioning and alignment of the permanent successors (figure 4).

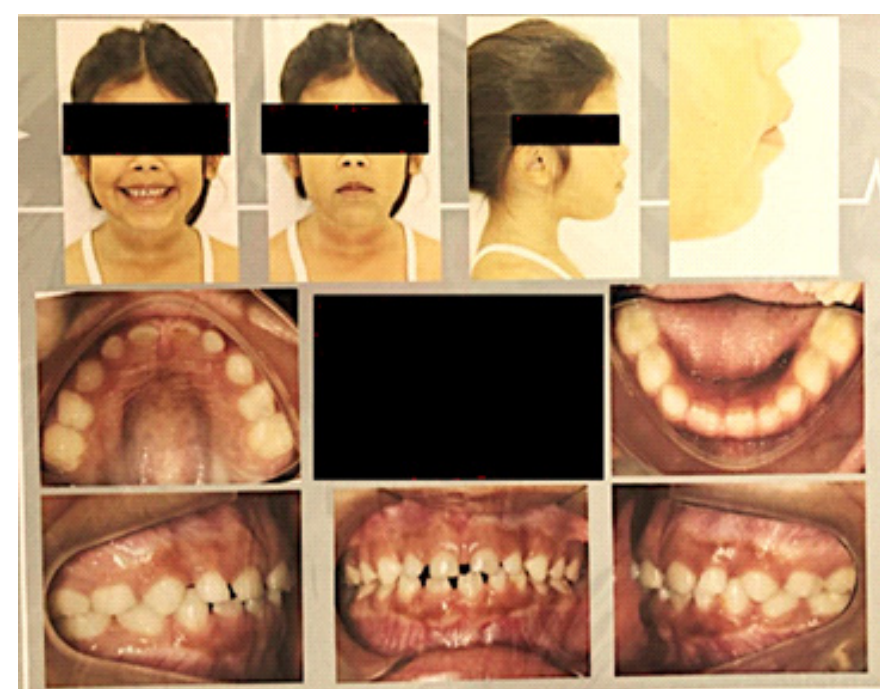

Figure 3. Photographs related to future orthodontic treatment taken on April 14th, 2018 - a (ML: midline).

An important deviation of dental midline to the right was found in the lower arch in relation to the face. This may have occurred due to the eruption sequence of the permanent teeth. Having erupt late in relation to tooth 31 (left mandibular central incisor), tooth 41 (right mandibular central incisor) may have deviated to the right. Comparing the two radiographs before and after the extraction of the fused teeth, tooth 41 had initiated eruption without traction and was well positioned, with no developmental anomalies after the extraction of the fused teeth (figure 4).

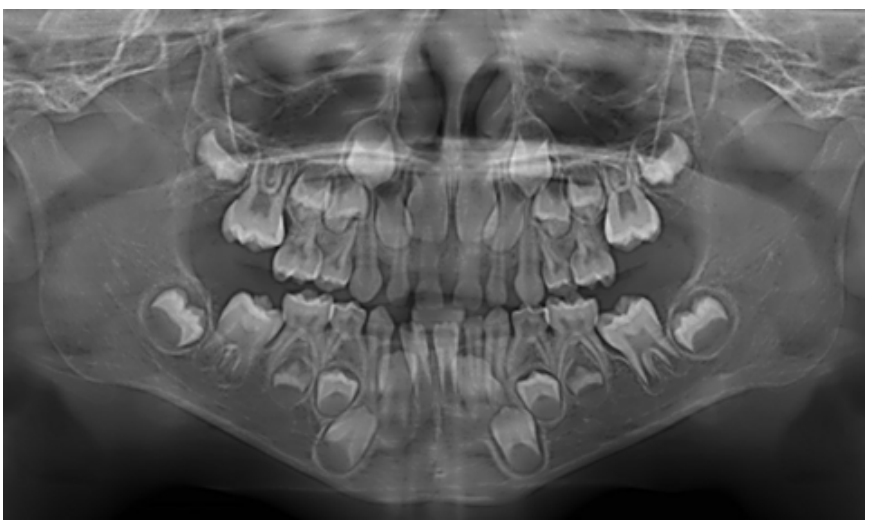

Figure 4. Panoramic x-ray taken on April 14th, 2018

The analysis of the photographs revealed a pleasant but convex facial profile with mild protrusion of both lips. The patient exhibited a harmonious smile, 
facial symmetry and the vertical dimension within the standards of normality. The occlusion exhibited a class I pattern with adequate horizonal and vertical anterior overjet (figure 5).

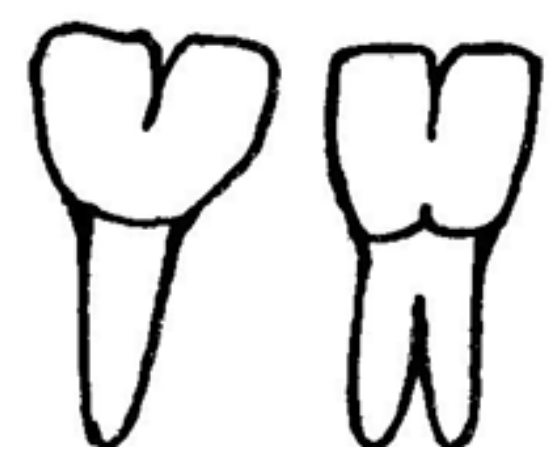

Figure 5. Schematic of difference between germination and fusion, respectively.

The Steiner cephalometric analysis (table 1) revealed that the maxilla was protruded, with the SNA angle increased by $4^{\circ}$, and the mandible was retracted, with the SNB diminished by $3^{\circ}$. Thus, the ANB angle of $9.5^{\circ}$ defined skeletal class II.

Thus, the case was of a patient with dental class I and skeletal class || with normal vertical growth. The very protruded mandibular central incisor (discrepancy of $11.63^{\circ}$ ) and slightly protruded maxillary central incisor (discrepancy of $1.91^{\circ}$ ) explained the protrusion of the upper and lower lips.

The guardian signed a statement of informed consent authorizing the report of the clinical case and the patient gave verbal consent, as stipulated in Resolution $466 / 2012$, since she was too young to sign the consent form. This case report received approval from the local institutional review board (certificate number: 2.688.903).

Table 1. Facial angles of six-year-old female patient.

\begin{tabular}{lccc}
\hline & Factors & Observed value & Norm/Classification \\
\hline 1 & S-N.A & $86.60^{\circ}$ & $82.00^{\circ}$ \\
2 & S-N.B & $77.12^{\circ}$ & $80.00^{\circ}$ \\
3 & A-N.B & $9.48^{\circ}$ & $2.00^{\circ}$ \\
4 & I.NB & $36.63^{\circ}$ & $25.00^{\circ}$ \\
5 & $1 / . N A$ & $23.91^{\circ}$ & $22.00^{\circ}$ \\
\hline
\end{tabular}

\section{DISCUSSION}

Fused teeth require a multidisciplinary approach. The combination of pediatric dentistry and orthodontics during the primary and mixed dentition phases is extremely important to the identification of dental anomalies and ensuring a better prognosis regarding treatment. The diagnosis in most cases is performed by a pediatric dentist, as the prevalence of this condition in greater in the primary dentition compared to the permanent dentition. The orthodontist has the function of managing the interception of this anomaly, which is a potential causal factor of malocclusion. The radiologist also makes an important contribution, as imaging exams assist in the clarification of difficult cases. The literature also proposes the use of computed tomography in complex cases. Moreover, depending on the expectations and dissatisfaction of the patient with his/her appearance, restorative dentistry may be necessary in some cases for the establishment of the normal anatomy of fused teeth [4].

Fused primary teeth are not rare and the treatment plan should be determined on a case-by-case basis. Fused teeth in the primary dentition have esthetic implications and can lead to malocclusion [8]. The etiology of this type of anomaly remains unknown, but the literature describes a combination of genetic and environmental factors [1]. In the present clinical case, there was no family history of tooth fusion. Other reports in the literature have also found no relation between genetic and environmental factors in cases of tooth fusion $[6,7,9]$. Fusion occurs in the developmental stages of dental morpho-differentiation. Pressure or physical force resulting in close contact between two tooth germs is also reported to be a possible cause of tooth fusion [8]. However, further evidence is needed to clarify the etiology of this developmental anomaly.

Tooth fusion can be confused with dental gemination, which is characterized clinically by an increased, bifid crown with a sulcus and arises from the separation of a single tooth germ due to invagination [10]. The distinguishing of a fused or twinned tooth can be determined using radiographic and clinical examinations (figure 5). A common differential diagnosis for fusion and gemination involves knowledge that twinned teeth cause crowding, whereas fusion most commonly causes the ectopic eruption of the permanent successor because of the prolonged retention of the fused tooth due to its larger root area [5]. During a routine clinical examination, 
fused teeth are often evident, as the anomaly has the appearance of a wide tooth with a bifid crown and a groove delineating the two crowns. The combination of a detailed patient history, radiographic exams and clinical evaluation is essential to the correct diagnosis and planning of treatment. Both periapical and panoramic radiographs are necessary $[4,5]$.

In the present case, the patient had a pleasant facial appearance, but the analysis indicated a lack of space. An orthodontic approach was indicated to intercept a severe malocclusion. The placement of a Hass or Hyrax expander is planned for the correction of the lack of space in the upper arch. A removable expander is indicated for the lower arch, as the mandibular incisors could not be projected further. Thus, the focus will be on a transverse gain to create space. Although the lack of space in the lower arch is critical, orthodontic treatment will be initiated with maxillary expansion, followed by mandibular expansion. Otherwise, posterior crossbite might occur [11].

A significant deviation of the midline to the right was found in the mandibular arch. This deviation occurred in the direction of the fusion due to the prolonged retention of the fused teeth. This midline deviation led us to the conclusion that the migration of tooth 41 to the right led to its occupation of the space for tooth 42 in the arch. Therefore, space needs to be created for tooth 42 to erupt normally in the arch. The non-interception of this anomaly implies important esthetic and occlusal problems, as asymmetry would develop in the inter-arch relation. After palatal expansion, space will be created in the mandible for tooth 42 .

The present case consists of a seven-year-old child and this period is not indicated for the correction of anteroposterior skeletal problems [2]. Based on the characteristics of craniofacial growth, there will be a need for a second orthodontic treatment phase near the pubescent growth spurt for the skeletal class II correction.

The fusion of primary mandibular central (tooth 81) and lateral (tooth 82) incisors in the present case significantly affected the normal evolution of the occlusion of the mixed dentition. The fusion resulted in a reduction in the arch and a lack of space for the normal eruption of the permanent mandibular anterior teeth.

This treatment plan is indicated as a protocol proposal for the specific treatment needs of this patient. It is important to identify this anomaly early and perform a detailed analysis of the occlusion in each case so that a conservative, individualized treatment plan can be instituted.

Morphological anomalies in the primary dentition are of considerable concern for pediatric dentists due to the possibility of associated clinical problems, such as dental caries, delayed exfoliation and anomalies in the permanent dentition (impaction of successors, supernumerary teeth or fused permanent teeth) [7]. Thus, the early diagnosis of such anomalies enables a more comprehensive long-term treatment plan, a more favorable prognosis and less need for complex orthodontic interceptions [2].

\section{CONCLUSION}

The occlusion of the primary dentition plays a significant role in the orientation of the occlusion of the subsequent permanent dentition. The most adequate dental intervention is the result of a multidisciplinary approach involving pediatric dentistry, radiology, orthodontic and restorative dentistry, considering the individual characteristics of each case as well as the expectations of each patient and his/her degree of cooperation with dental treatment.

\section{Collaborators}

A COSTA, BS NASCIMENTO, JLC SILVA, AMC SANTOS, treated the clinical case and prepared the manuscript. SC COSTA CRUZ. And MLMF FERNANDES. Oriented the planning and execution of the clinical case, contributed to the writing of the manuscript and performed the revision of the manuscript.

\section{REFERENCES}

1. Crespi R, Capparé P, Crespi G, Giudice G, Gastaldi G, Gherlone E. Dental implants placed in periodontally infected sites in humans. Clin Implant Dent Relat Res. 2017;19(1):131-139. http://dx.doi.org/10.1111/ cid.12425

2. Neto AF, Carreiro AFP, Barbosa CMR. The issue of the removable partial denture in modern dentistry. Odontol ClínCient. 2011;10:125-128.

3. Santos WB, Fernandes LEBA, Souza HAV, Santos JMB, Santos VCB, Franco AVM. Fusão bilateral em incisivos laterais inferiores: relato de caso. RvAcBO. 2018;7(3):179-182.

4. Lochib S, Indushekar KR, Saraf BG, Sheoran N, Sardana D. Occlusal characteristics and prevalence of assotiated dental anomalies in the primary dentition. J Epidemiol Glob Health. 
2015;5(2):151-157. http://dx.doi.org/10.1016/j.jegh.2014. 07.001

5. Tomizawa M, Shimizu A, Hayashi ST, Noda T. Bilateral maxillary fused primary incisors accompanied by succedaneous supernumerary teeth report of a case. Int J Paediatr Dent. 2002;12(3):223-227. http://dx.doi.org/10.1046/j.1365-263x. 2002.00351.x

6. Kumar P, Kaur J, Verma KG, Goyal V, Juneja J. Fusion of primary teeth- An odontogenic anomaly. J Oral Med Oral Surg Oral Pathol Oral Radiol. 2018; 4(1):53-55. http://dx.doi. org/10.18231/2395-6194.2018.00125

7. Zhu M, Chao L, Ren S, Zintong L, Miao L, Sun W. Fusion of a supernumerary tooth to right mandibular second molar: a case report and literature review. Int J Clin Exp Med. 2015;8(8):11890-11895.

8. Gharderi F, Rafiee A. Bilateral supernumerary deciduous maxillary lateral incisors with fu-sion: report of a rare case. J Dent (Shiraz). 2016;17(1):67-70.
9. Gupta T, Manuja N. Bilateral fusion of primary mandibular incisors: a rare case report. J Clin Diagn Res. 2015; 9(12):ZJ01. http://dx.doi.org/10.7860/JCDR/2015/16077.6933

10. Guimarães SPA, Jorge KO, Fontes MJF, Ramos-Jorge ML, Araújo CTP, Ferreira EF, et al. Impact of malocclusion on oral health-related quality of life among schoolchildren. Braz Oral Res. 2018;32(95). http://dx.doi.org/10.1590/1807-3107 bor2018.vol32.0095

11. Mehta V. Fusion of primary mandibular anterior teeth associated with partial anodontia of primary and permanent dentition: a case report. J Dent Health Oral Disord Ther. 2015;3(3):310-312. http://dx.doi.org/10.15406/jdhodt.2015.03.00090

Received on: 16/6/2019 Final version resubmitted on: 17/8/2019 Approved on: 24/9/2019 